\title{
Investigating the residential electricity consumption-income nexus in Morocco: a stochastic impacts by regression on population, affluence, and technology analysis
}

\author{
Charifa Haouraji ${ }^{1}$, Badia Mounir ${ }^{2}$, Ilham Mounir ${ }^{2}$, Laila Elmaazouzi ${ }^{2}$, Abdelmajid Farchi ${ }^{1}$ \\ ${ }^{1}$ IMMI Laboratory, Faculty of sciences and techniques, Hassan 1st University Settat, Morocco \\ ${ }^{2}$ LAPSSII Laboratory, High School of Thechnology, Safi, Morocco
}

\begin{tabular}{l} 
Article Info \\
\hline Article history: \\
Received Jan 20, 2021 \\
Revised Oct 26, 2021 \\
Accepted Nov 10, 2021 \\
\hline Keywords: \\
Electricity consumption \\
Logarithmic mean Divisia \\
index model \\
Morocco \\
Residential sector \\
STIRPAT model
\end{tabular}

\begin{abstract}
In a comprehensive LMDI-STIRPAT-ARDL framework, this research investigates the residential electricity consumption (REC)-income nexus in Morocco for the period 1990 to 2018. The logarithmic mean Divisia index (LMDI) results show that economic activity and electricity intensity are the leading drivers of Morocco's REC, followed by population and residential structure. And then, the LMDI analysis was combined with stochastic impacts by regression on population, affluence, and technology (STIRPAT) analysis and the bounds testing approach to search for a long-run equilibrium relationship. The empirical results show that REC, economic growth, urbanization, and electricity intensity are cointegrated. The results further show that there exists a U-shaped relationship between per capita gross domestic product (GDP) and REC: an increase in per capita GDP reduces REC initially; but, after reaching a turning point (the GDPPC level of $17,145.22 \mathrm{Dh}$ ), further increases in per capita GDP increase REC. Regarding urbanization, the results reveal that it has no significant impact on Morocco's REC. The stability parameters of the short and long-term coefficients of residential electricity demand function are tested. The results of these tests showed a stable pattern. Finally, based on the findings mentioned above, policy implications for guiding the country's development and electricity planning under energy and environmental constraints are given.
\end{abstract}

This is an open access article under the CC BY-SA license.

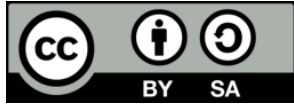

\section{Corresponding Author :}

Charifa Haouraji

IMII Laboratory, Faculty of sciences and techniques, Hassan 1st University

FST of Settat, Km 3, B.P: 577 Road of Casablanca, Settat, Morocco

Email: haouraji.charifa@gmail.com

\section{INTRODUCTION}

Energy is one of the key sectors which is becoming an increasingly important issue for sustainable growth. The large challenge for countries, especially developing countries, is not the lack of energy resources, but mainly the mobilization of necessary investments in the energy area. Therefore, it becomes absolutely necessary to build appropriate energy infrastructures and develop alternative technologies. In this regard, Morocco should be prepared to ensure its economic and social development by meeting sustainably to growing energy needs.

In 2018, Morocco's total energy consumption was dominated by fossil fuels (74\%), followed by electricity (18\%), natural gas and biomass (8\%) [1]. The end-use of energy differs by sectors. As shown in Figure 1, after the transportation sector $(37 \%)$, the residential sector was the second-largest final energy 
consumer $(25 \%)$, followed by the manufacturing sector $(20 \%)$ and the commercial sector (18\%). As Morocco imports almost all of its energy needs, it remains highly vulnerable to rising energy prices. Imports account for $93.6 \%$ of national requirements [2], which include oil products, crude oil, coal, Algerian natural gas, and electricity.

The greatest opportunity to conserve energy and minimize greenhouse gases is through the residential sector-which truth be told, seems to be both accessible and more profitable than other sectors [3]. This advocated the setting of very challenging national goals aimed at lessening residential energy use. One of these goals is to save approximately $770 \mathrm{GWh}$ of residential electricity consumption (REC) per year. To achieve these goals, residential consumption levels require to be disrupted and this disruption needs a detailed understanding of the determinants of residential consumption dynamics to enable effective intervention.

In 2018, the major consumed energy in the Moroccan residential sector is the liquefied petroleum gas (LPG) (64\%), whilst the other main consumers of energy are electricity (24\%) and biomass (13\%) [1]. These sources of energy are used for food preparation/preservation domestic, space heating/cooling and water heating. Through Figure 2, we can see that there is a significant reduction in the use of biomass in favor of electricity and LPG. This could be attributed to the introduction of the global rural electrification program and the increase in the rate of urbanization. According to international energy agency (IEA) [1], Moroccan REC has increased significantly over the last ten years compared to the other energy sources consumed in the sector. Indeed, REC has increased by $63 \%$ in the last ten years (the average annual growth rate is around 5\%), while the increase of LPG has been around 59\% (the average annual growth rate is around $4.7 \%$ ). Moreover, compared to other sectors, the residential one absorbs a large share of electricity. These facts make REC an important and interesting area of investigation.

There have been a few empirical studies directed to help understand the nexus between economic development, urbanization, and electricity use in developing countries, especially those in North Africa. These countries are characterized by massive indebtedness, significant population growth, and low investments since the 1980s. Along with other countries in North Africa, Morocco faces several energy challenges that may compromise economic growth and the improvement of living conditions. Electric power can then be a major constraint on the country's economic development due both to the weak supply and the high demand in the context of growing urbanization.

In light of the above motivations and in order to add to the current literature, an empirical study is conducted to investigate whether there is a long-run relationship between per capita gross domestic product (GDP), urbanization, and REC in Morocco. The following are the contributions of this work; Firstly, a logarithmic mean Divisia index (LMDI) decomposition analysis is carried out in order to identify and analyze the main drivers of changes in residential electricity consumption (REC) in Morocco, which is the first to our knowledge. Secondly, to deal with the question of balance between REC, economic and demographic development, the LMDI analysis was combined with the econometric techniques such as the stochastic impacts by regression on population, affluence, and technology (STIRPAT) procedure and the autoregressive distributed lag (ARDL) bounds testing approach to cointegration. This is new in literature. Moreover, the current study uses a regressive model, in contrast to most previous studies that have always included Morocco in panel regression analysis [4], [5]. Each country has specific characteristics that are hard to identify with panel regression models. Finally, since few studies have searched for an environmental Kuznets curve (EKC) association between electricity use and economic development, we investigated whether one exists.

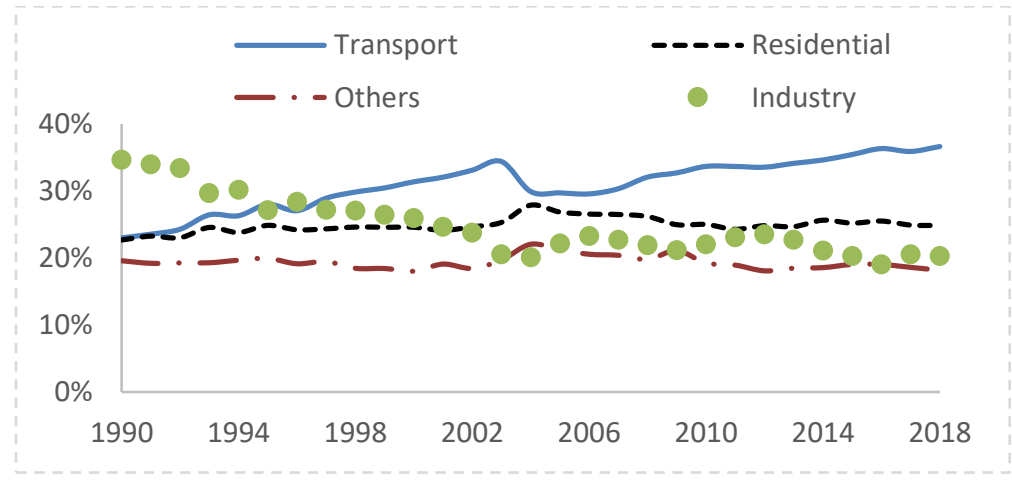

Figure 1. Combined graphical plots of the share of total final consumption (TFC) by sector in Morocco [1] 


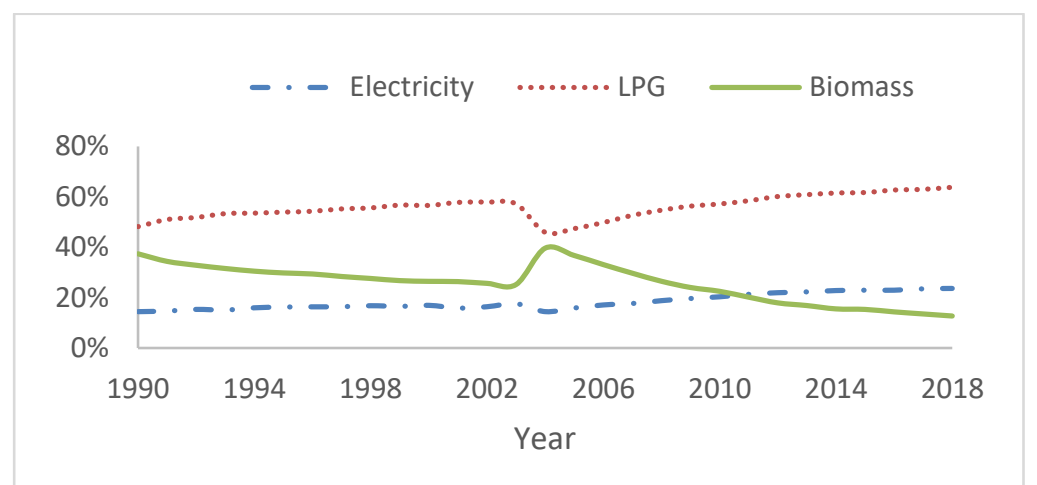

Figure 2. Final energy sources consumed in Moroccan residential sector [1]

The rest of this study is structured as follows: section 2 is the literature review. Section 3 focuses on sources of data and methodological procedures applied. Section 4 describes the estimation of our model with a focus on stationarity and cointegration in particular. Section 5 illustrates the empirical findings, section 6 presents the policy implications, and section 7 presents the conclusions.

\section{REVIEW OF RELATED LITERATURE}

\subsection{Theoretical literature}

Both scientists and policy makers have been attracted to the interaction between urbanization, economic growth, and residential electricity consumption. The empirical findings were found to be mixed and inconsistent as some researchers support a negative relationship, and others report that the relationship is not significant, while some are exposing the positive relationship. For further discussion, this particular section will provide an overview of the previous literature.

Many studies exploring the factors impacting energy consumption have mainly used two fundamental decomposition techniques, which are index decomposition analysis (IDA) and structural decomposition analysis (SDA). The IDA method has been widely applied as it presents more advantages over to the SDA method [6]. Two large models of the IDA method are thus emerging, mainly driven by the works of Kaya [7] and Dietz and Rosa [8]: The Kaya identity model and the impacts by regression on population, affluence, and technology (IPAT) model. The latter models have been further improved by some researchers. For instance, Ang [9] developed the LMDI decomposition method based on extended Kaya identity, which is widely used to examine the influence mechanism of energy consumption. York et al. [10] also improved the IPAT model by introducing the STIRPAT approach. Lately, these models have been widely used to analyze energy use and particularly electricity consumption. Some researchers have even combined the two models such as Li et al. [6] and Chai et al. [11].

\subsection{Empirical literature}

In the existing literature, numerous investigations have been dedicated to the study of decomposition in the residential sector. Rogan et al. [12] used the LMDI method to break down increases in gas use in Ireland's residential sector. They argued that the customer numbers effect was the primary driver of the increase in gas consumption. Yeo et al. [13] utilized the LMDI technique to define the primary drivers of residential $\mathrm{CO}_{2}$ emissions. The outcomes show that in China and India, GDP's growth is the significant supporter of $\mathrm{CO}_{2}$ emissions, while energy intensity has the potential to reduce the residential emissions. For the case of China, Fan et al. [14] employed the Divisia decomposition method to assess urbanization's impact on residential energy use. They estimated that 15.4 percent of the overall shift in residential energy use was due to the effects of urbanization. Huang [15] employed the same method to explore Taiwan's REC during the 2014-2017 period. The study reveals that climate was the main driver of energy growth. However, in the national literature, two studies emphasize decomposition analysis in case of Morocco, while neither research has examined the residential sector. In the first study, Kharbach and Chfadi [16] attempted to identify the key contributors to the Moroccan transport sector's carbon emission. They concluded that the ownership factor and population are the main drivers of the total change in transport energy use. Engo [17], who paired the LMDI approach with Tapio method to analyze $\mathrm{CO}_{2}$ emissions from industrial development in Egypt, Morocco, Algeria, and Tunisia, performed the second study. The findings revealed that the economic structural effect has significantly contributed to Morocco's decoupling. 
The other preferred approach by researchers to investigate the overall energy use of various sectors is the STIRPAT model. For instance, Liddle and Lung [18] applied the STIRPAT model on 17 developed nations for the time frame 1960-2005 and showed that both domestic residential energy and electricity usage were positively influenced by urbanization. Liddle [19] analyzed the impact of the population by age groups on REC using the cointegration-STIRPAT approach. Their empirical evidence showed that the youngest and oldest population increase REC, while the middle ones decrease it. Hasanov and Mikayilov [20] examined the relationship between age groups of the population and REC by incorporating economic growth. Their results indicate that GDP leads to decrease electricity consumption. A similar inference was reached by Yang et al. [21], who pointed out the effect of urbanization on Pakistan's use of residential electricity. They suggested that urbanization and income increase REC in Pakistan. The majority of residential energy and revenue investigations, focused on cross-countries or panel research, pay very little attention to regions such as Africa and the Middle East. In the case of Morocco, most studies [22], [23] conducted have investigated energy use as a gross term or carbon dioxide emissions and disregard the disparity between the household sector and other development sectors.

\section{MODEL CONSTRUCTION}

3.1. Data

The present study covers the 1990 to 2018 annual sample period. Population, urbanization rate, GDP per capita and final household expenditure data are collected from the national "Haut comissariat au plan" [24]. Furthermore, data on REC are provided by the "International energy agency" [1]. More information on the variables used are summarized in Table 1.

Table 1. Variables' descriptions

\begin{tabular}{ccc}
\hline Variables & Interpret & Unit \\
\hline Residential electricity consumption & Total electricity consumption in residential sector & Ktoe \\
Population size & Total population & Thousands \\
Urbanization rate & Urban population/Total population & $\%$ \\
Economic growth & GDP per capita & MDh \\
Household's final expenditure & Consumer spending of residents & MDh \\
\hline
\end{tabular}

\subsection{Methodology}

This study aimed to explore the long-run relationship between income, urbanization, and REC in Morocco. For achieving this goal and, as shown in Figure 3, the LMDI model based on an extended Kaya identity was used first to decompose and define factors impacting electricity use in the residential sector, over the period 1990-2018. Secondly, the leading contributors to the REC found were divided into economic and demographic indicators when using STIRPAT approach to estimate the net effect of each driver of the REC. These methods were chosen due to their growing popularity and adaptability to the case of our study. A detailed description of each of these techniques is given in the following sections.

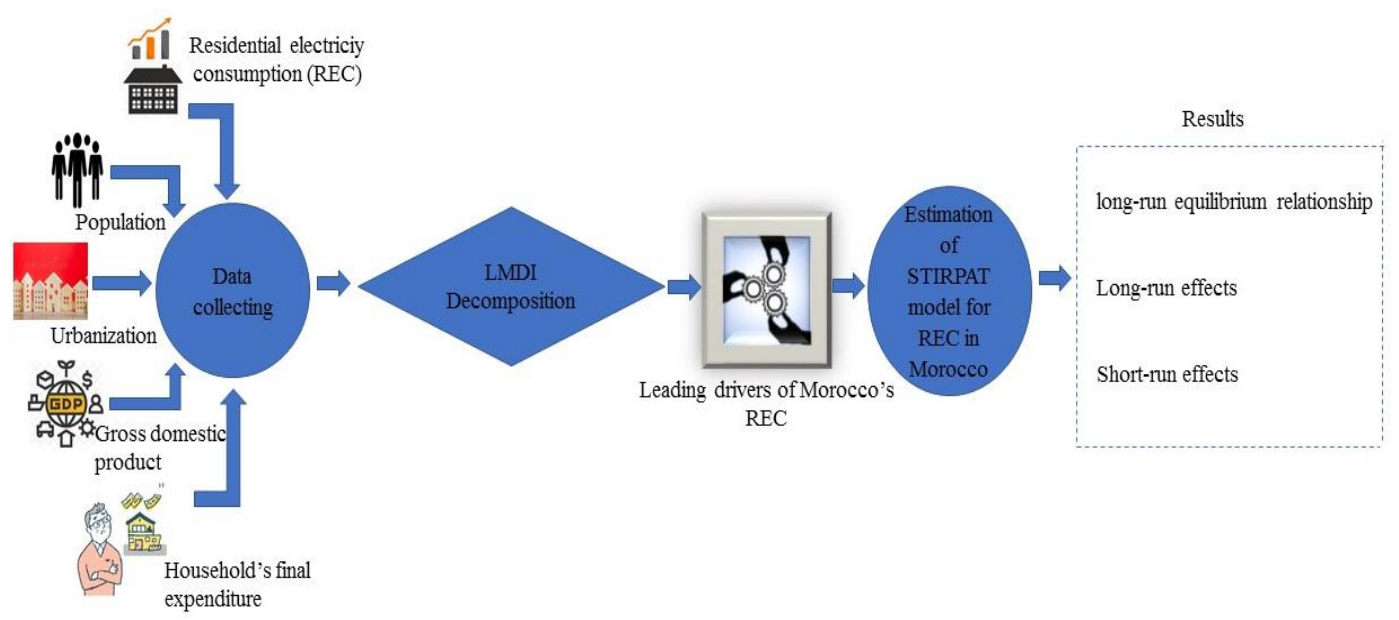

Figure 3. Our approach for investigating the residential electricity consumption-income nexus in Morocco 


\subsection{Overview of leading factors of REC based on LMDI decomposition}

In this section, the LMDI is employed to estimate the contribution of a set of variables to the variation of electricity consumption in Morocco's residential sector. Indeed, the LMDI method's choice is based on its robust theoretical foundations, flexibility, feasibility, and the ability to develop a complete decomposition, where the results do not include any unexplained residual term [9]. This method has also been extensively debated in the context of energy use measurement. Then, the decomposition equation of our target variable is shown in (1):

$$
\begin{aligned}
\text { REC } & =\frac{\text { REC }}{\operatorname{EXP}} \times \frac{\text { EXP }}{\text { GDP }} \times \frac{\text { GDP }}{P} \times P \\
& =I \times S \times Y \times P
\end{aligned}
$$

where I refers to electricity intensity and expresses the overall efficiency of energy and residential activity; S represents the residential structure and reflects the contribution of housing sector to economic growth; $\mathrm{Y}$ is per capita GDP and $\mathrm{P}$ is population.

The LMDI approach suggested by Ang [9] is then used to quantify the changes in REC ( $\triangle \mathrm{REC)}$ through time ( $\mathrm{t}-1$ to $\mathrm{t}) . \triangle \mathrm{REC}$ is the sum of the intensity effect $(\Delta \mathrm{I})$ caused by changes in electricity intensity, the residential structure effect $(\Delta \mathrm{S})$ caused by consumer spending changes, the economic activity effects $(\Delta \mathrm{Y})$ caused by per capita GDP changes, and the total population effect $(\Delta \mathrm{P})$ caused by quantitative population changes. The expressions for the LMDI decomposition for Morocco's REC are as (2):

$$
\begin{aligned}
& \Delta \mathrm{REC}^{=} \mathrm{REC}_{\mathrm{t}}-\mathrm{REC}_{\mathrm{t}-1}=\Delta \mathrm{I}+\Delta \mathrm{S}+\Delta \mathrm{Y}+\Delta \mathrm{P} \\
& \Delta \mathrm{I}=\mathrm{L}\left(\mathrm{REC}_{\mathrm{t}}, \mathrm{REC}_{\mathrm{t}-1}\right) \ln \frac{\mathrm{I}_{\mathrm{t}}}{\mathrm{I}_{\mathrm{t}-1}} \\
& \Delta \mathrm{S}=\mathrm{L}\left(\mathrm{REC}_{\mathrm{t}}, \mathrm{REC}_{\mathrm{t}-1}\right) \ln \frac{\mathrm{S}_{\mathrm{t}}}{\mathrm{S}_{\mathrm{t}-1}} \\
& \Delta \mathrm{Y}=\mathrm{L}\left(\mathrm{REC}_{\mathrm{t}}, \mathrm{REC}_{\mathrm{t}-1}\right) \ln \frac{\mathrm{Y}_{\mathrm{t}}}{\mathrm{Y}_{\mathrm{t}-1}} \\
& \Delta \mathrm{P}=\mathrm{L}\left(\mathrm{REC}_{\mathrm{t}}, \mathrm{REC}_{\mathrm{t}-1}\right) \ln \frac{\mathrm{P}_{\mathrm{t}}}{\mathrm{P}_{\mathrm{t}-1}}
\end{aligned}
$$

where $\mathrm{L}(\mathrm{a}, \mathrm{b})$ is the logarithmic average of two positive numbers: " $a$ " and " $\mathrm{b}$ " and it is expressed as (7):

$$
L(a, b)=\frac{a-b}{\ln a-\ln b}
$$

Using the decomposition components given in (2), we estimated the driving factors of electricity related residential consumption during the investigation period. Table 2 and Figure 4 show the results. Decomposition findings reveal that per capita GDP is the principal factor driving the REC changes. The results further show a positive economic growth effect impact in most years except for 1992, 1993, 1995, 1997, 1999 and 2016. The changes in per capita GDP make a cumulative contribution of 359.53 ktoe to the growth of REC, which represents $46.62 \%$ of the overall electricity change. This suggests that per capita GDP contributes directly to annual rises in Morocco's REC.

Electricity intensity and population are the second largest driving factors causing the changes in REC. The decomposition findings show that electricity intensity plays a significant role in rising electricity use in residential sector. The accumulated effect is an increase of $219.53 \mathrm{ktoe}$, which represents $28.47 \%$ of the overall change of REC. Moreover, in certain years, the reverse signs between electricity intensity and REC variations suggest that electricity intensity effect has restrained REC. Theoretically, the decrease in electricity intensity would have a substantial effect in the future on reducing the use of residential electricity.

Furthermore, the measurement results of population variation shown in Table 2 reveal that its contribution to the residential related electricity consumption is large and positive. The changes in population scale accounted for $23.35 \%$ of the total change in REC. Indeed, an expansion in population effect contributes to an increase in electricity demand as shown in Figure 4. The main reason may be that urban population is increasing, which has a relatively large impact on REC. Indeed, the urbanization trend promotes domestic electricity use, which could be explained in two ways: i) the migration of rural inhabitants to cities improves 
universal access to power, and ii) the purchase of modern electrical appliances by the new urban citizens would increase electricity demand [25]

Finally, the residential structure has the smallest influence on the changes in REC. The accumulated effect has been an increase of $12.02 \mathrm{ktoe}$, which accounts for $1.56 \%$ of the total change in electricity. This result suggests that energy expenditures does not vary significantly, which may be explained by several reasons: The price of kilowatt hour $(\mathrm{kWh})$ was fixed until 2012; Morocco has a moderate climate so there is no need for heating in many regions; and electricity needs are offset by LPG as it is subsidized by the state.

Table 2. Decomposition results of Moroccan residential electricity consumption

\begin{tabular}{|c|c|c|c|c|c|}
\hline & $\Delta \mathrm{I}$ & $\Delta \mathrm{S}$ & $\Delta \mathrm{Y}$ & $\Delta \mathrm{P}$ & $\triangle \mathrm{REC}$ \\
\hline $1990-1991$ & -2.17 & 12.59 & 9.94 & 3.76 & 24.13 \\
\hline 1991-1992 & 23.62 & 4.05 & -8.76 & 4.08 & 23.00 \\
\hline $1992-1993$ & 13.56 & -1.59 & -6.22 & 4.25 & 10.00 \\
\hline 1993-1994 & -3.71 & 4.79 & 21.49 & 4.43 & 27.00 \\
\hline 1994-1995 & 27.21 & 4.18 & -19.49 & 4.10 & 16.00 \\
\hline 1995-1996 & -26.87 & 3.04 & 29.71 & 4.11 & 10.00 \\
\hline 1996-1997 & 27.93 & -8.17 & -9.01 & 4.25 & 15.00 \\
\hline 1997-1998 & 3.02 & -4.41 & 17.95 & 4.44 & 21.00 \\
\hline 1998-1999 & 3.34 & 2.05 & -1.00 & 4.61 & 9.00 \\
\hline $1999-2000$ & 9.62 & -0.22 & 1.85 & 4.74 & 16.00 \\
\hline $2000-2001$ & -22.16 & -20.35 & 19.84 & 4.67 & -18.00 \\
\hline 2001-2002 & 11.95 & 1.30 & 6.09 & 4.67 & 24.00 \\
\hline $2002-2003$ & 15.76 & 0.19 & 17.01 & 5.04 & 38.00 \\
\hline 2003-2004 & 12.89 & -1.34 & 14.02 & 5.44 & 31.00 \\
\hline 2004-2005 & 32.14 & 0.15 & 8.82 & 5.88 & 47.00 \\
\hline 2005-2006 & 17.42 & -5.08 & 30.21 & 6.46 & 49.00 \\
\hline 2006-2007 & 11.63 & 5.46 & 11.98 & 6.93 & 36.00 \\
\hline 2007-2008 & 8.24 & 8.92 & 26.43 & 7.41 & 51.00 \\
\hline 2008-2009 & -3.65 & -1.31 & 18.15 & 7.81 & 21.00 \\
\hline 2009-2010 & 10.96 & 1.57 & 16.37 & 8.09 & 37.00 \\
\hline $2010-2011$ & 15.61 & 1.69 & 27.14 & 8.56 & 53.00 \\
\hline 2011-2012 & 21.43 & 8.31 & 13.12 & 9.14 & 52.00 \\
\hline $2012-2013$ & -0.70 & -10.29 & 25.48 & 9.51 & 24.00 \\
\hline 2013-2014 & 23.49 & 3.77 & 12.10 & 9.64 & 49.00 \\
\hline 2014-2015 & 3.41 & -18.64 & 29.21 & 9.01 & 23.00 \\
\hline $2015-2016$ & -5.16 & 22.82 & -0.01 & 9.35 & 27.00 \\
\hline 2016-2017 & 7.50 & -3.70 & 28.50 & 9.69 & 42.00 \\
\hline $2017-2018$ & -16.79 & 2.21 & 18.61 & 9.97 & 14.00 \\
\hline 1990-2018 & 219.53 & 12.02 & 359.53 & 180.06 & 771.13 \\
\hline
\end{tabular}

Source: IEA [1], HCP [24], own calculations

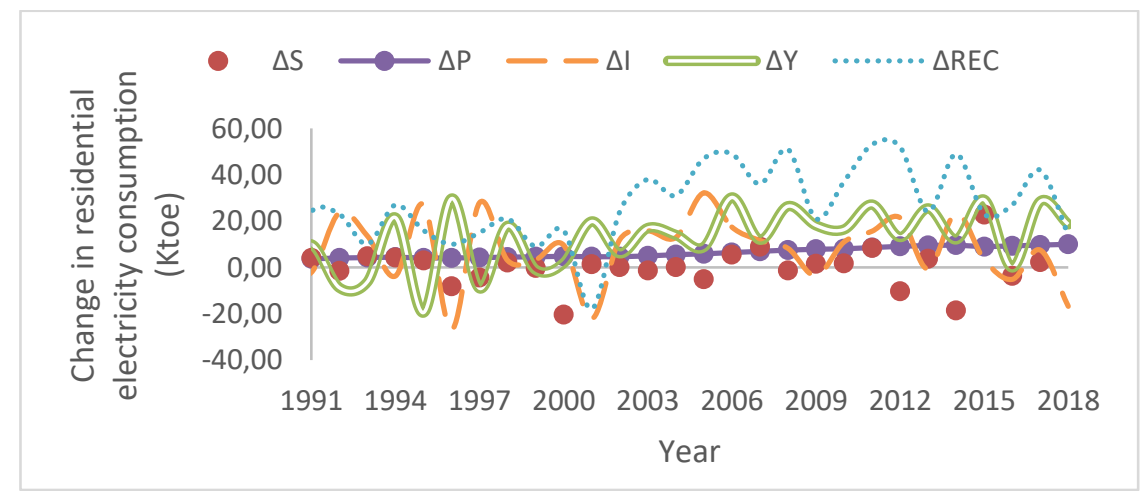

Figure 4. Factor decomposition for residential electricity consumption changes

\subsection{STIRPAT model for REC in Morocco}

The STIRPAT model is used in the majority of research looking at the impact of social and economic factors on $\mathrm{CO}_{2}$ emissions and, more recently, energy use. As part of this study, the same model will be employed in our empirical analysis. A description of the STIRPAT modeling framework follows. The STIRPAT model retains the multiplicative form of accounting identity developed by Ehrlich and Holden [26] presented in the following form (8): 


$$
\mathrm{I}=\mathrm{PAT}
$$

In this model, $\mathrm{I}$ is environmental pressure, $\mathrm{P}$ is population, $\mathrm{A}$ is the affluence, and $\mathrm{T}$ is technology. Note that (8) is an identity. Therefore, it cannot be estimated or used to test hypotheses. These limits led to the development of its stochastic version and thus, the IPAT became the STIRPAT. The standard formula of the STIRPAT is expressed as (9):

$$
I=\mathrm{aP}^{\mathrm{b}_{1}} \mathrm{~A}^{\mathrm{b}_{2}} \mathrm{~T}^{\mathrm{b}_{3}} \mathrm{e}
$$

where a is a constant term, $b_{1}, b_{2}, b_{3}$ are the coefficients to be estimated econometrically, and e is the error term. The (9) is then log-transformed to (10):

$$
\ln \mathrm{I}=\mathrm{a}+\mathrm{b}_{1} \ln \mathrm{P}+\mathrm{b}_{2} \ln \mathrm{A}+\mathrm{b}_{3} \ln \mathrm{T}+\mathrm{e}
$$

The STIRPAT model provides researchers a flexibility by modifying (and/or) augmenting the standard specification depending on the research object. For instance, number of studies use electricity consumption as a dependent variable instead of environmental impact [18]-[21]. Therefore, our STIRPAT model will incorporate the variables that are found to more contribute on electricity consumption from the LMDI decomposition results (electricity intensity, per capita GDP, and population) to learn more about how these variables influence changes in electricity demand.

As mentioned above, the three factors that most influence the REC changes from LMDI are: per capita GDP, electricity intensity and population. Electricity demand and economic growth are significant predictors of each other, as Akadiri et al. [27] pointed out. Moreover, many researchers have demonstrated the existence of environmental Kuznets curve (EKC) between economic development, energy consumption, and environmental pollution [23], [28]. Therefore, to investigate whether there is an EKC curve between REC and income, we will introduce a quadratic term of the per capita GDP into our STIRPAT model.

On the other hand, most of the empirical studies analyzing REC incorporate urbanization as a control variable rather than an independent variable. Some scholars found that urbanization is driving REC [29]-[31]. However, there have also been adverse conclusions, which means that increasing urbanization leads to reduce residential consumption [32], [33]. This may be due to the transition from traditional fuels to commercial fuels. Finally, other scholars suggest that impact of urbanization on the residential energy consumption depends on different stages of country's economic development [34], [35]. To thoroughly reflect the effect of population size on Moroccan REC, this analysis used urbanization to replace the population component, as done by Lin and Jiang [36], Wang et al. [37], Shahbaz et al. [38], and Chai et al. [11]. Then, the STIRPAT model for Morocco's REC can be written as (11):

$$
\operatorname{lnREC}_{t}=a+b_{1} \ln U_{t}+b_{2} \ln Y_{t}+b_{3}\left(\ln Y_{t}\right)^{2}+b_{4} \operatorname{lnI}_{t}+e_{t}
$$

where, $R E C_{t}$ is residential electricity consumption, $U_{t}$ is the urbanization rate expressed as a proportion of urban population in total population, $Y_{t}$ represents per capita GDP expressed by the constant prices in 2010 and $I_{t}$ is the residential electricity intensity expressed as the proportion of electricity consumption in final household expenditure. The sample period was from 1990 to 2018.

\section{ESTIMATION OF STIRPAT MODEL}

This paper employed the ARDL bounds testing approach to estimate the STIRPAT model and investigate the long-run relationship between Morocco's residential electricity consumption $\left(\ln R E C_{t}\right)$, urbanization $\left(\ln U_{t}\right)$, per capita GDP $\left(\ln Y_{t}\right)$, and electricity intensity $\left(\ln I_{t}\right)$.

\subsection{Unit root tests}

The first step is to study the stationary character of the variables under study. Most of the statistical properties of estimation methods are applied only to stationary series, otherwise we could have a spurious result [39]. A stationary series is characterized by constant mean and variance, generally none of its characteristics change over time.

In this regard, we apply three different unit root tests, namely augmented Dickey-Fuller (ADF), Phillips-Perron (PP) and Kwiatkowski-Phillips-Schmidt-Shi (KPSS). In fact, the KPSS and PP tests are used as alternative tests to validate the ADF test results. This is especially significant due to a specific characteristic of each method. 


\subsection{ARDL bounds cointegration test}

Once the order of integration of variables has been specified, the following step is to investigate the presence of cointegration. To the current finish, we elect to use the ARDL bounds testing approach, introduced, and developed by Pesaran et al. [40]. The latter approach was chosen due to its adaptability to small sample data, which is the case for this study. For small data, critical values to be compared with our computed $\mathrm{F}$ statistics are readily available. In addition, the test simultaneously provides both long-run and short-run tests. The ARDL approach goes through several steps. The (11) is transformed as (12):

$$
\begin{aligned}
\Delta \operatorname{lnREC}_{\mathrm{t}}=\beta_{0}+ & \sum_{\mathrm{i}=1}^{\mathrm{p}} \rho_{\mathrm{i}} \Delta \operatorname{lnREC}_{\mathrm{t}-1}+\sum_{\mathrm{i}=0}^{\mathrm{p}} \mu_{\mathrm{i}} \Delta \ln \mathrm{U}_{\mathrm{t}-1}+\sum_{\mathrm{i}=0}^{\mathrm{p}} \alpha_{\mathrm{i}} \Delta \ln \mathrm{Y}_{\mathrm{t}-1} \\
& +\sum_{\mathrm{i}=0}^{\mathrm{p}} \eta_{\mathrm{i}} \Delta \ln \mathrm{Ir}_{\mathrm{t}-1}^{2}+\sum_{\mathrm{i}=0}^{\mathrm{p}} \sigma_{\mathrm{i}} \Delta \operatorname{lnI} \mathrm{t}-1+\lambda_{1} \operatorname{lnREC} \mathrm{C}_{\mathrm{t}-1} \\
& +\lambda_{2} \ln \mathrm{U}_{\mathrm{t}-1}+\lambda_{3} \ln _{\mathrm{t}-1}+\lambda_{4} \ln \mathrm{Y}_{\mathrm{t}-1}^{2}+\lambda_{1} \ln \mathrm{I}_{\mathrm{t}-1}+\varepsilon_{\mathrm{t}}
\end{aligned}
$$

where $\beta_{0}$ is the constant term and $\varepsilon_{t}$ white noise term. The terms with the $\Delta$ signs denote the error correction model, while those with the $\lambda$ coefficient denote the long-run relationship.

The "Bounds test" is employed to verify the cointegration relationship among variables. It consists of conducting an F-test or Wald test on the null hypothesis $\lambda_{1}=\lambda_{2}=\lambda_{3}=\lambda_{4}=\lambda_{5}=0$ against the alternative hypothesis $\lambda_{1} \neq \lambda_{2} \neq \lambda_{3} \neq \lambda_{4} \neq \lambda_{5} \neq 0$. Then, the F-statistic is calculated and compared with two critical thresholds, i.e a lower critical bound (LCB) and an upper critical bound (UCB). The null hypothesis of no cointegration is not rejected, whereas if the statistic is above the UB. If the LB value exceeds our calculated F-statistic, there is no cointegration. Besides, if the F-statistic lies somewhere in between the critical bounds, the "Bounds test" is deemed inconclusive. If the long-run relationship is verified, the error correction model that defines short-run impacts can then be estimated using (13):

$$
\begin{aligned}
\Delta \operatorname{lnREC}_{\mathrm{t}}=\beta_{0}+ & \sum_{\mathrm{i}=1}^{\mathrm{p}} \rho_{\mathrm{i}} \Delta \operatorname{lnREC_{\mathrm {t}-1}}+\sum_{\mathrm{i}=0}^{\mathrm{p}} \mu_{\mathrm{i}} \Delta \ln \mathrm{U}_{\mathrm{t}-1}+\sum_{\mathrm{i}=0}^{\mathrm{p}} \alpha_{\mathrm{i}} \Delta \ln \mathrm{Y}_{\mathrm{t}-1} \\
& +\sum_{\mathrm{i}=0}^{\mathrm{p}} \eta_{\mathrm{i}} \Delta \ln \mathrm{Y}_{\mathrm{t}-1}^{2}+\sum_{\mathrm{i}=0}^{\mathrm{p}} \sigma_{\mathrm{i}} \Delta \operatorname{lnI}_{\mathrm{t}-1}+\mu \mathrm{ECM}_{\mathrm{t}-1}+\varepsilon_{\mathrm{t}}
\end{aligned}
$$

where $E C M_{t-1}$ represents the estimate of the lagged error correction term and indicates the short-run convergence rate towards the equilibrium long run path.

\section{EMPIRICAL RESULTS AND DISCUSSION}

Table 3 summarizes some descriptive statistics associated with the variables studied. The Jarque-Bera test indicate that all the variables (REC, urbanization, per capita GDP, and electricity intensity) have a normal distribution. This supports us for further analysis to investigate the relation between the RECincome nexus in Morocco. Moreover, the analysis of the values of the variation coefficient (CV) shows that the electricity intensity series has the highest variability, followed by that of REC, GDP per capita and urbanization.

Table 3. Descriptive statistics

\begin{tabular}{ccccc}
\hline Variables & LnREC & LnU & LnY & LnI \\
\hline Mean & 6.122704 & 4.016027 & 9.926574 & 0.237754 \\
Median & 6.066108 & 4.008612 & 9.902767 & 0.222671 \\
Maximum & 6.862758 & 4.133565 & 10.29165 & 0.459211 \\
Minimum & 5.219635 & 3.883624 & 9.605419 & -0.114906 \\
Std. Dev. & 0.503986 & 0.069818 & 0.237380 & 0.177444 \\
Jarque-Bera & 1.959208 & 0.983869 & 2.697375 & 1.862169 \\
Probability & 0.375460 & 0.611442 & 0.259581 & 0.394126 \\
CV & 0.082314 & 0.017384 & 0.023913 & 0.746334 \\
Observation & 29 & 29 & 29 & 29 \\
\hline
\end{tabular}

Table 4 deals with the results of the ADF, PP and KPSS unit root tests. We found that all the variables have the unit root problem at level with intercept and trend. The tests show that REC, urbanization, per capita GDP, and electricity intensity are integrated at order 1(I(1)). As no series is I(2), the ARDL approach choice was appropriate. 


\begin{tabular}{cccc}
\multicolumn{4}{c}{ Table 4. Unit root tests results } \\
\hline Series & $\begin{array}{c}\text { ADF } \\
\text { t-value }\end{array}$ & $\begin{array}{c}\text { PP } \\
\text { t-value }\end{array}$ & $\begin{array}{c}\text { KPSS } \\
\text { t-value }\end{array}$ \\
\hline $\ln$ REC & $-1.76(0)$ & $-1.51[3]$ & $0.69[3]$ \\
$\ln \mathrm{U}$ & $0.29(1)$ & $-1.28[4]$ & $0.69[4]$ \\
$\ln \mathrm{Y}$ & $-1.76(3)$ & $0.50[1]$ & $0.67[4]$ \\
$\ln \mathrm{I}$ & $-1.67(0)$ & $-1.90[2]$ & $0.68[4]^{*}$ \\
$\Delta \ln \mathrm{REC}$ & $-4.16(0)^{*}$ & $-4.12[1]^{* *}$ & $0.18[3]^{*}$ \\
$\Delta \ln \mathrm{U}$ & $-2.85(0)^{* *}$ & $-2.85[0]^{* *}$ & $0.20[4]^{*}$ \\
$\Delta \ln \mathrm{Y}$ & $-3.92(2)^{*}$ & $-9.16[3]^{*}$ & $0.24[1]^{*}$ \\
$\Delta \ln \mathrm{I}$ & $-3.61(3)^{* *}$ & $-7.49[2]^{*}$ & $0.22[2]^{*}$ \\
\hline Note: $*$, $*$ and *** show significance at $1 \%, 5 \%$ and $10 \%$ respectively. () and [] \\
indicate lag order and bandwidth based on AIC for ADF and PP unit root tests \\
respectively. $\Delta$ represents first difference.
\end{tabular}

The ARDL approach relies on two steps. We first decide an appropriate lag length of the variables using unrestricted VAR. The F-statistic differs according to different levels of lag length. The akaike information criterion (AIC), Schwarz information criterion (SIC), and Hannan and Quinn (HQ) criteria are then used to select the optimal lag length. Through the results of the four criteria presented in Table 5, the optimal lag length is 3. Second, we examine the cointegration among variables by applying the ARDL bounds testing and computing F-statistic. The current study focuses only on the model with REC as the dependent variable. The findings reported in Table 6 shows that F-statistic (5.021) exceed the UCB value $(\mathrm{I}\{1\}=4.01)$ at $5 \%$ significance level. In this case, the null hypothesis of no cointegration was rejected and the existence of a long run relationship among REC, urbanization, per capita GDP, and electricity intensity was confirmed.

Since REC and its factors are cointegrated, the long-run impacts of the variables are estimated and summarized in Table 7 . The results showed a positive contribution of urbanization to REC. A $1 \%$ add in urbanization is associated with $0.68 \%$ increase in REC. This implies that urbanization process in Morocco is gainfully contributing to the electricity sector. The findings are supported by Gates and Yin [41], Zaman et al. [42] and Yang et al. [21] who reported that electricity consumption is affected positively by urbanization. Fobi et al. [43] also found that rural customers use 50\% less electricity than urban customers in Kenya. Note that Morocco and Kenya are part of the same group of income "Lower middle-income economies", according to the classification made by the WDI [2]. Regarding the Moroccan energy situation, the positive impact might relieve pressure on butane gas consumption and automatically reduced the country's expenses of the compensation fund. Note that support for butane, sugar and flour cost the state 17 billion Dh in 2018. Butane gas absorbs a large part of these expenses, reaching 12.09 billion Dh in 2018.

The estimated coefficients related to the linear and non-linear term of per capita GDP appear to be significant at $10 \%$. As shown in Table 7 , results suggest that an increase in per capita GDP will initially reduce REC; but, after reaching a turning point (the per capita GDP level of 17,154.22 Dh), further increases in per capita GDP increase REC. Therefore, our findings support a U-shaped relationship between economic growth and REC in Morocco, which supports the claim of Hasanov and Mikayilov [20]. This result suggests that a higher level of income undermines the electricity efficiency in the residential sector.

The effect of electricity intensity is positive and significant at $1 \%$, indicating that a $1 \%$ increase in electricity intensity will increase REC by 1.49 by keeping other variables constant. The plausible logic for these outcomes is that the country will experience social and environment changes. Morocco already starting to experience more extreme and intense weather events, such as extended heat waves and winter storms, which increase residential heating and air conditioning intensity. Similarly, the decrease in household size will impact electricity intensity. The upside is that Morocco has started producing electricity from the emerging renewable sources: wind energy and solar energy. Several projects are underway to accelerate this process and reach the objectives set by 2030 to produce $52 \%$ of electricity from renewable sources. This would decrease our external reliance on energy and reduce our Spanish imports of electricity.

The estimated short-run coefficients are presented in Table 8. The results indicate that the impact of urbanization is negative but statistically insignificant. Similarly, the impacts of the linear and non-linear term of per capita GDP are statistically insignificant. Finally, the relationship between electricity intensity and REC is positive and significant at $1 \%$.

As further detailed in Table 8, the $E C M_{t-1}$ estimated at -0.629 is statistically significant at $1 \%$ significance level and has a negative sign. This result implies that approximately $63 \%$ of the shocks to the system are restored in the next year. It will take about seventeen months to achieve the stable long run equilibrium path. Moreover, the short run model diagnostic tests are performed to determine if the model meets all the assumptions of the classical linear regression model. The White test confirms the absence of heteroscedasticity of the residues whereas the Jarque-Bera test shows that they follow a normal distribution. 
The Lagrange multiplier test result reveals that there are no serial correlations in the model residuals. The Ramsey test shows that the short model is well specified. Furthermore, we applied the cumulative sum (CUSUM) and CUSUM of square (CUSUMQ) tests to examine the stability of the estimated model. As shown in Figure 5, the plots of both CUSUM and CUSUMQ statistical tests remain within the 5\% critical lines. Therefore, we concluded that the estimated coefficients are reliable.

Table 5. Var lag order selection criteria

\begin{tabular}{ccccccc}
\hline Lag & $\log \mathrm{L}$ & LR & FPE & AIC & SIC & HQ \\
\hline 0 & 254.82 & NA & $3.10 \mathrm{e}-15$ & -19.21 & -18.97 & -19.14 \\
1 & 449.21 & 299.05 & $7.10 \mathrm{e}-21$ & -32.24 & -30.79 & -31.82 \\
2 & 490.55 & 47.70 & $2.57 \mathrm{e}-21$ & -33.50 & -30.84 & -32.73 \\
3 & 543.61 & $40.81^{*}$ & $6.21 \mathrm{e}-22^{*}$ & $-35.66^{*}$ & $-31.79^{*}$ & $-34.54^{*}$ \\
\hline
\end{tabular}

Note: LR: sequential modified LR test statistic (each test at 5\% level). FPE: Final prediction error. AIC: Akaike information criterion. SC: Schwarz Information criterion. HQ: HannanQuin information criterion. * Indicates lag order selected by the criterion

Table 6. Test results of cointegration tests

\begin{tabular}{|c|c|c|c|c|c|}
\hline Dependent variable & & Function & & F-statistics & \\
\hline Model 1 & & $\mathrm{~F}\left(\operatorname{lnREC} / \ln U, \ln \mathrm{Y}, \ln \mathrm{Y}^{2}, \ln \mathrm{I}\right)$ & & $5.02 * *$ & \\
\hline Model 2 & & $\mathrm{~F}\left(\ln \mathrm{U} / \ln \mathrm{REC}, \ln \mathrm{Y}, \ln \mathrm{Y}^{2}, \ln \mathrm{I}\right)$ & & $10.33^{*}$ & \\
\hline Model 3 & & $\mathrm{~F}\left(\ln \mathrm{Y} / \ln \mathrm{REC}, \ln \mathrm{U}, \ln \mathrm{Y}^{2}, \ln \mathrm{I}\right)$ & & $11.16^{*}$ & \\
\hline Model 4 & & $\mathrm{~F}\left(\ln \mathrm{Y}^{2} / \ln \mathrm{REC}, \ln \mathrm{U}, \ln \mathrm{Y}, \ln \mathrm{I}\right)$ & & $10.97 *$ & \\
\hline Model 5 & & $\mathrm{~F}\left(\ln \mathrm{I} / \ln \mathrm{REC}, \ln \mathrm{U}, \ln \mathrm{Y}, \ln \mathrm{Y}^{2}\right)$ & & $8.30^{*}$ & \\
\hline \multicolumn{6}{|c|}{ Asymptotic critical values } \\
\hline $1 \%$ & & $5 \%$ & & $10 \%$ & \\
\hline LCB & UCB & LCB & $\mathrm{UCB}$ & LCB & UCB \\
\hline 3.74 & 5.06 & 2.86 & 4.01 & 2.45 & 3.52 \\
\hline
\end{tabular}

Note: $* * *$ and $* * *$ significant at $1 \%, 5 \%$ and $10 \%$ levels respectively. The optimal lag determined by AIC. Upper and lower critical bounds are obtained from Perasan et al. [40]

Table 7. Long run results, dependent variable is ln REC

\begin{tabular}{|c|c|c|c|c|}
\hline Variable & Coefficient & Std. error & t-statistic & Prob. values \\
\hline Constant & 63.60 & 33.61 & 1.89 & $0.08 * * *$ \\
\hline $\ln U$ & 0.68 & 0.25 & 2.69 & $0.05 * *$ \\
\hline $\ln \mathrm{Y}$ & -12.63 & 6.50 & -1.94 & $0.07 * * *$ \\
\hline $\ln \mathrm{I}$ & 1.49 & 0.24 & 6.21 & $0.00^{*}$ \\
\hline EKC & Turning point formula & Turning point value & Per capita GDP highest value & Conclusion \\
\hline Morocco & $\begin{array}{c}\text { Antilog of - }\left(0,5^{*}\right. \\
\text { Coefficient attached with } Y \\
\text { Coefficient attached with the quadratic } \\
\text { term of } Y\end{array}$ & 17,154.22 Dh & $29,485.52 \mathrm{Dh}$ & $\begin{array}{c}\text { EKC } \\
\text { relationship }\end{array}$ \\
\hline
\end{tabular}

Note: $* * *$ and $* * *$ significant at $1 \%, 5 \%$ and $10 \%$ levels respectively

Table 8. Short run results, dependent variable is $\Delta \ln$ REC

\begin{tabular}{|c|c|c|c|c|}
\hline Variables & Coefficient & Std. Error & t-statistic & Prob. values \\
\hline Constant & 40.05 & 18.55 & 2.15 & $0.04 * *$ \\
\hline$\Delta \ln R E C_{t-1}$ & 0.37 & 0.22 & 1.63 & 0.12 \\
\hline$\Delta \ln \mathrm{U}$ & -0.01 & 0.51 & -0.00 & 0.99 \\
\hline$\Delta \ln \mathrm{Y}$ & 12.51 & 7.27 & 1.72 & 0.10 \\
\hline$\Delta \ln Y^{2}$ & -0.58 & 0.37 & -1.57 & 0.13 \\
\hline$\Delta \ln \mathrm{I}$ & 1.13 & 0.15 & 7.23 & $0.00 *$ \\
\hline$E C T_{t-1}$ & -0.62 & 0.22 & -2.78 & $0.01 * *$ \\
\hline R-squared & 0.99 & & & \\
\hline Adj. R-squared & 0.99 & & & \\
\hline F-statistic & $2722.21 *$ & & & \\
\hline Durbin-Watson tests & 1.72 & & & \\
\hline Diagnostic tests & F-statistic & Prob. Value & & \\
\hline$\chi^{2}$ NORMAL & 0.911 & 0.634 & & \\
\hline$\chi^{2}$ SERIAL & 3.535 & 0.062 & & \\
\hline$\chi^{2} \mathrm{ARCH}$ & 0.002 & 0.959 & & \\
\hline$\chi^{2}$ REMSAY & 2.700 & 0.107 & & \\
\hline
\end{tabular}

Note: $* * *$ and $* * *$ significant at $1 \%, 5 \%$ and $10 \%$ levels respectively. Normality of error term, serial correlation, autoregressive conditional heteroskedasticity and functional of short run model is indicated by $\chi^{2}$ NORMAL, $\chi^{2}$ SERIAL , $\chi^{2}$ ARCH, $\chi^{2}$ REMSAY respectively 

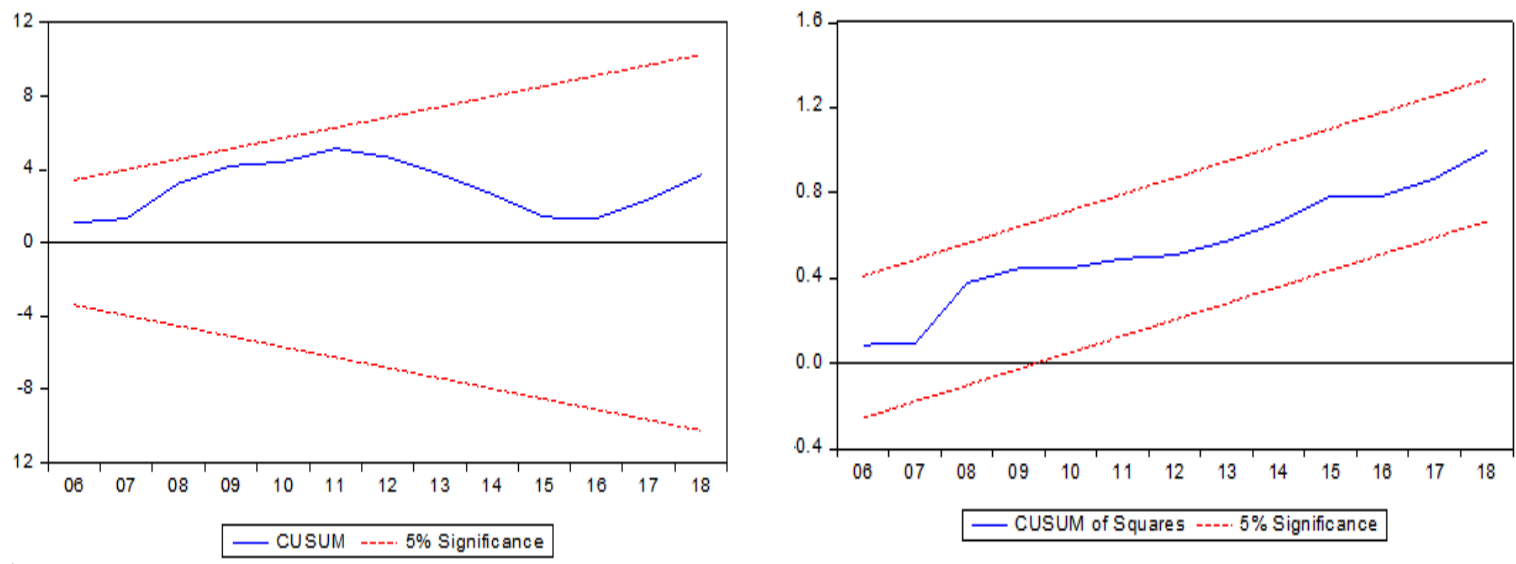

Figure 5. Plot of CUSUM and CUSUMQ residuals of the estimated model

\section{POLICY IMPLICATIONS}

The empirical results discussed above have the following important policy implications for Morocco: Firstly, the positive impact of urbanization on electricity consumption calls for an important need for the implementation of urban policies to harness other economically feasible sources of energy. Policy makers must be able to meet the challenges of an increase in electricity demand due to the increase in the urban population. Limiting urbanization to control electricity demand cannot be considered, as reducing urbanization can have a negative effect on economic development. Rather, we should be moving towards using other additional sources of energy. According to Alola and Alola [44] and Alola and Yildirim [45], the use of renewable energy improves the real income. Efforts must therefore be made to promote investment in renewable energies and develop urban policies that encourage their use. At the same time, electrical energy saving projects should be implemented to reduce electrical intensity in urban areas as well as at the national level, in particular by providing subsidies to replace old inefficient electrical appliances with more efficient items.

Secondly, since the REC is expected to grow after reaching a high-income level and economic development cannot be restrained, a pressure on electricity expenses is expected. Indeed, the government should implement the policies of controlling excessive electricity consumption for too high comfort. The pricing systems for distribution of electricity need to be reviewed in order to lead Moroccan households to turn towards the renewable energy. Thirdly, the relationship between electricity intensity and residential electricity consumption was found positive as expected. In Morocco, the rate of integration of renewable energies into the residential energy mix is weak despite having a strong solar and wind potential. The government should be urged to support and subsidy programs to install a non-emitting and sustainable heating and cooling systems. In addition, incorporating the sustainable development notion into building standards and requiring the property developers to comply with these standards can also contribute to the completion of this project.

Finally, all these directives cannot come into being if the population is not engaged. Therefore, political authorities, media and educational circles must collaborate and planned electricity conservation awareness campaigns. Only the involvement of civil society may guarantee an efficient use of electricity. The proposed implications are in line with the recommendations suggested by the IEA [1] which also emphasized the importance of fostering the clean energy transition. Unfortunately, we cannot have a clear vision of the future of renewable energies in the residential sector as the government has not set any targets in this context.

\section{CONCLUSION}

This study attempted to investigate the residential electricity consumption for Morocco through the decomposition and cointegration analysis over the period 1990-2018. According to the factor decomposition analysis, the overall effect of electricity intensity, residential structure, economic growth, and population scale was positive. The impact of economic growth was the main driver of residential electricity consumption with a contribution of $(46.62 \%)$, followed by electricity intensity $(28.47 \%)$, population scale $(23.35 \%)$, and the residential structure $(1.56 \%)$.

Based on the results of LMDI approach, an empirical analysis is conducted by employing the STIRPAT model. Firstly, traditional unit root tests such as ADF, PP and KPSS were applied on all the series that are found to be integrated at I(1). Moreover, the cointegration relationship was tested using the ARDL 
bounds testing approach. The empirical findings corroborate the existence of cointegration among residential electricity consumption, economic growth, urbanization, and electricity intensity. Furthermore, the estimate of the long-run relationship shows that a $1 \%$ add in urbanization and electricity intensity will lead to a $0.68 \%$, and $1.49 \%$ respectively, increase in the total residential electricity consumption. Finally, the study reveals that a U-shaped relationship exists between income growth and residential electricity consumption: REC initially declines with income growth, then starts to increase after hitting a turning point.

\section{REFERENCES}

[1] International Energy Agency, "Energy policies beyond IEA countries: Chile 2018," OECD, 2018.

[2] "Updated country income classifications for the World Bank's 2019 fiscal year." The World Bank. 2019. https://datahelpdesk.worldbank.org/knowledgebase/articles/906519-world-bank-country-and-lending-groups (Accessed 10 April 2019).

[3] "Pathways to a low-carbon economy, version 2 of the global greenhouse gas abatement cost curve," McKinsey and Company, 2009.

[4] M. Gabbasa, K. Sopian, Z. Yaakob, M. R. F. Zonooz, A. Fudholi, and N. Asim, "Review of the energy supply status for sustainable development in the Organization of Islamic Conference," Renewable and Sustainable Energy Reviews, Elsevier, vol. 28(C), pp. 18-28, Dec. 2013, doi: 10.1016/j.rser.2013.07.045.

[5] A. Boukhelkhal and I. Bengana, "Cointegration and causality among electricity consumption, economic, climatic and environmental factors: Evidence from North-Africa region," Energy, Elsevier vol. 163(C), pp. 1193-1206, Nov. 2018, doi: 10.1016/j.energy.2018.08.163.

[6] J. Li, Y. Chen, Z. Li, and Z. Liu, "Quantitative analysis of the impact factors of conventional energy carbon emissions in Kazakhstan based on LMDI decomposition and STIRPAT model," Journal of Geographical Sciences, vol. 28, no. 7, pp. 1001-1019, Jul. 2018, doi: 10.1007/s11442-018-1518-5.

[7] Y. Kaya, "Impact of Carbon Dioxide Emission Control on GNP Growth: Interpretation of Proposed Scenarios," IPCC Response Strategies Working Group Memorandum 1989, IPCC Energy and Industry Subgroup, Response Strategies Working Group, 1990.

[8] T. Dietz and E.A. ROSA, "Rethinking the environmental impacts of population, affluence, and technology," Human Ecology Review, vol. 1, no. 2, pp. 277-300, 1994.

[9] B. W. Ang, "Decomposition analysis for policymaking in energy:," vol. 32, no. 9, pp. 1131-1139, Jun. 2004, doi: 10.1016/s03014215(03)00076-4.

[10] R. York, E. A. Rosa, and T. Dietz, "STIRPAT, IPAT and ImPACT: analytic tools for unpacking the driving forces of environmental impacts," Ecological Economics, vol. 46, no. 3, pp. 351-365, Oct. 2003, doi: 10.1016/S0921-8009(03)00188-5.

[11] J. Chai, T. Liang, K. K. Lai, Z. G. Zhang, and S. Wang, "The future natural gas consumption in China: Based on the LMDISTIRPAT-PLSR framework and scenario analysis," Energy Policy, vol. 119, pp. 215-225, Aug. 2018, doi: 10.1016/j.enpol.2018.04.049.

[12] F. Rogan, C. J. Cahill, and B. P. Ó. Gallachóir, "Decomposition analysis of gas consumption in the residential sector in Ireland," Energy policy, vol. 42, pp. 19-36, Mar. 2012, doi: 10.1016/j.enpol.2011.10.059.

[13] Y. Yeo, D. Shim, J.-D. Lee, and J. Altmann, "Driving forces of CO2 emissions in emerging countries: LMDI decomposition analysis on china and India's residential sector," Sustainability, vol. 7, no. 12, pp. 16108-16129, Dec. 2015, doi: $10.3390 / \mathrm{su} 71215805$.

[14] J.-L. Fan, Y.-J. Zhang, and B. Wang, "The impact of urbanization on residential energy consumption in China: An aggregated and disaggregated analysis," Renewable and Sustainable Energy Reviews, vol. 75, pp. 220-233, Aug. 2017, doi: 10.1016/j.rser.2016.10.066.

[15] Y.-H. Huang, "Examining impact factors of residential electricity consumption in Taiwan using index decomposition analysis based on end-use level data," Energy, vol. 213, p. 119067, Dec. 2020, doi: 10.1016/j.energy.2020.119067.

[16] M. Kharbach and T. Chfadi, "CO2 emissions in Moroccan road transport sector: Divisia, cointegration, and EKC analyses," Sustainable Cities and Society, vol. 35, pp. 396-401, Nov. 2017, doi: 10.1016/j.scs.2017.08.016.

[17] J. Engo, "Driving forces and decoupling indicators for carbon emissions from the industrial sector in Egypt, Morocco, Algeria, and Tunisia," vol. 28, no. 12, pp. 14329-14342, Nov. 2020, doi: 10.1007/s11356-020-11531-3.

[18] B. Liddle and S. Lung, "Age-structure, urbanization and climate change in developed countries: revisiting STIRPAT for disaggregated population and consumption-related environmental impacts," vol. 31, no. 5, pp. 317-343, Feb. 2010, doi: 10.1007/s11111-010-0101-5.

[19] B. Liddle, "Consumption-driven environmental impact and age structure change in OECD countries," Demographic Research, vol. 24, pp. 749-770, May 2011, doi: 10.4054/DemRes.2011.24.30.

[20] F. J. Hasanov and J. I. Mikayilov, "The impact of age groups on consumption of residential electricity in Azerbaijan," vol. 50, no. 4, pp. 339-351, Oct. 2017, doi: 10.1016/j.postcomstud.2017.09.005.

[21] Y. Yang, J. Liu, Y. Lin, and Q. Li, “The impact of urbanization on China's residential energy consumption,” Structural Change and Economic Dynamics, vol. 49, pp. 170-182, Jun. 2019, doi: 10.1016/j.strueco.2018.09.002.

[22] S. Narayan and N. Doytch, "An investigation of renewable and non-renewable energy consumption and economic growth nexus using industrial and residential energy consumption,” vol. 68, pp. 160-176, Oct. 2017, doi: 10.1016/j.eneco.2017.09.005.

[23] R. Berahab, "Carbon dioxide emissions and economic growth in Morocco: An analysis of the kuznets environmental curve," (in French), OCP Policy Center, 2017.

[24] "HCP statistical database (BDS)." High Commission for Planning of Morocco. 2018. [Online]. Available: http://bds.hcp.ma/indicators/23 (Accessed Sep 19, 2019).

[25] P. Holtedahl and F. L. Joutz, "Residential electricity demand in Taiwan," vol. 26, no. 2, pp. 201-224, Mar. 2004, doi: 10.1016/j.eneco.2003.11.001.

[26] P. R. Ehrlich and J. P. Holdren, "Impact of population growth," vol. 171, no. 3977, pp. 1212-1217, Mar. 1971, doi: 10.1126/science.171.3977.1212.

[27] S. S. Akadiri, A. A. Alola, G. Olasehinde-Williams, and M. U. Etokakpan, "The role of electricity consumption, globalization and economic growth in carbon dioxide emissions and its implications for environmental sustainability targets," vol. 708, Mar. 2020, Art. no. 134653 , doi: 10.1016/j.scitotenv.2019.134653. 
[28] Y. He and B. Lin, "Investigating environmental Kuznets curve from an energy intensity perspective: Empirical evidence from China," Journal of Cleaner Production, vol. 234, pp. 1013-1022, Oct. 2019, doi: 10.1016/j.jclepro.2019.06.121.

[29] C. Weber and A. Perrels, "Modelling lifestyle effects on energy demand and related emissions," Energy Policy, vol. 28, no. 8, pp. 549-566, Jul. 2000, doi: 10.1016/s0301-4215(00)00040-9.

[30] F. Halicioglu, "Residential electricity demand dynamics in Turkey," Energy Economics, vol. 29, no. 2, pp. 199-210, Mar. 2007, doi: 10.1016/j.eneco.2006.11.007.

[31] P. Sheng and X. Guo, "Energy consumption associated with urbanization in China: Efficient and inefficient-use," Energy, vol. 165, pp. 118-125, Dec. 2018, doi: 10.1016/j.energy.2018.09.161.

[32] S. Pachauri, "An analysis of cross-sectional variations in total household energy requirements in India using micro survey data," Energy Policy, vol. 32, no. 15, pp. 1723-1735, Oct. 2004, doi: 10.1016/s0301-4215(03)00162-9.

[33] Q. Wang, "Effects of urbanisation on energy consumption in China," Energy Policy, vol. 65, pp. 332-339, Feb. 2014, doi: 10.1016/j.enpol.2013.10.005.

[34] P. Poumanyvong and S. Kaneko, "Does urbanization lead to less energy use and lower CO2 emissions? A cross-country analysis," Ecol. Econ., vol. 70, no. 2, pp. 434-444, Dec. 2010, doi: 10.1016/j.ecolecon.2010.09.029.

[35] P. Poumanyvong, S. Kaneko, and S. Dhakal, "Impacts of urbanization on national transport and road energy use: Evidence from low, middle and high income countries," Graduate School for International Development and Cooperation (IDEC), Hiroshima University, vol. 46, pp. 268-277, Jul. 2012, doi: 10.1016/j.enpol.2012.03.059.

[36] B. Q. Lin and Z. J. Jiang, "Environmental Kuznets curve prediction and influencing factors analysis of carbon dioxide in China," Manag. World, vol. 04, pp. 27-36, 2009.

[37] Z. Wang, F. Yin, Y. Zhang, and X. Zhang, "An empirical research on the influencing factors of regional CO2 emissions: Evidence from Beijing city, China," Appl. Energy, vol. 100, pp. 277-284, Dec. 2012, doi: 10.1016/j.apenergy.2012.05.038.

[38] M. Shahbaz, A. R. Chaudhary, and I. Ozturk, "Does urbanization cause increasing energy demand in Pakistan? Empirical evidence from STIRPAT model," Energy, vol. 122, pp. 83-93, Mar. 2017, doi: 10.1016/j.energy.2017.01.080.

[39] C. W. J. Granger and P. Newbold, "Spurious regressions in econometrics," J. Econ., vol. 2, no. 2, pp. 111-120, Jul. 1974, doi: 10.1016/0304-4076(74)90034-7.

[40] M. H. Pesaran, Y. Shin, and R. J. Smith, "Bounds testing approaches to the analysis of level relationships," J Appl Econ., vol. 16, no. 3, pp. 289-326, 2001, doi: 10.1002/jae.616.

[41] D. F. Gates and J. Z. Yin, "Urbanization and energy in China: Issues and implications,” Routledge, 2018 , pp. 351-371.

[42] K. Zaman, M. M. Khan, M. Ahmad, and R. Rustam, "Determinants of electricity consumption function in Pakistan: Old wine in a new bottle," Energy Policy, vol. 50, pp. 623-634, Nov. 2012, doi: 10.1016/j.enpol.2012.08.003

[43] S. Fobi, V. Deshpande, S. Ondiek, V. Modi, and J. Taneja, "A longitudinal study of electricity consumption growth in Kenya," Energy policy, vol. 123, pp. 569-578, Dec. 2018, doi: 10.1016/j.enpol.2018.08.065.

[44] A. A. Alola and U. V. Alola, "Agricultural land usage and tourism impact on renewable energy consumption among Coastline Mediterranean Countries," Energy \& Environment, vol. 29, no. 8, pp. 1438-1454, Jun. 2018, doi: 10.1177/0958305x18779577.

[45] A. A. Alola and H. Yildirim, "The renewable energy consumption by sectors and household income growth in the United States," International Journal of Green Energy, vol. 16, no. 15, pp. 1414-1421, Sep. 2019, doi: 10.1080/15435075.2019.1671414. 